\title{
Course of diabetic retinopathy following cataract
} surgery

\author{
Ayala Pollack, Shlomo Dotan, Moshe Oliver
}

\begin{abstract}
Five patients with mild to moderate retinopathy to both eyes underwent complicationfree cataract surgery in one eye. Within three months of surgery deterioration of the retinopathy was observed in the operated eye only. In four patients there was an increase of intraretinal haemorrhages and hard exudates, accompanied by clinically significant macular oedema manifested as retinal thickening and extensive fluorescein leakage from both the macular and the peripapillary capillary networks. Of these four patients one also developed retinal ischaemia, evident ophthalmoscopically by flame-shaped haemorrhages and cotton-wool spots and angiographically by areas of capillary non-perfusion. The fifth patient showed proliferation of new blood vessels and vitreous haemorrhage. Diabetic patients scheduled for cataract surgery should undergo a thorough preoperative evaluation of any existing retinopathy. Postoperatively they should be followed up at close intervals so that any progression of retinopathy can be promptly detected and considered for laser treatment.
\end{abstract}

In diabetic patients without diabetic retinopathy visual acuity after cataract surgery is generally favourable and similar to that of non-diabetic patients. ${ }^{1-5}$ However, if diabetic retinopathy is present at the time of surgery the prognosis may

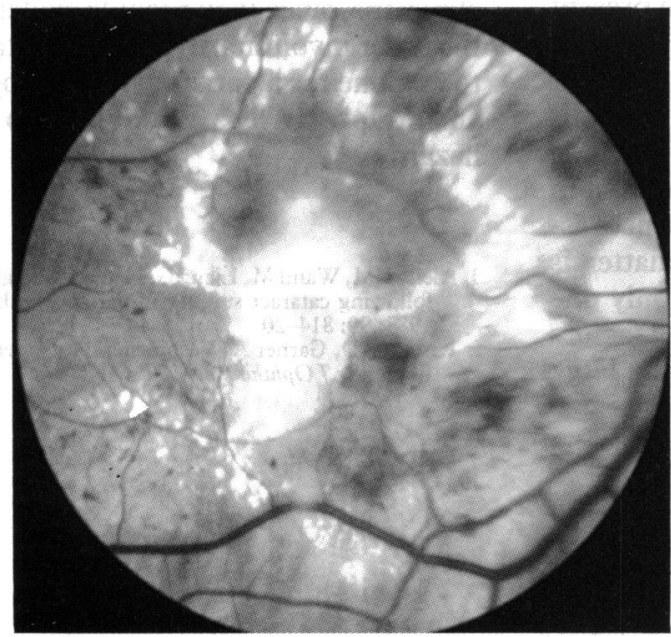

Figure 1A be much worse. ${ }^{1-36}$ Jaffe and Burton ${ }^{7}$ described six patients with diabetic retinopathy who developed severe exudative macular oedema after cataract surgery, with poor final visual acuity. There was no progression of diabetic retinopathy in the non-operated fellow eye. We also have observed a rapid deterioration of diabetic retinal changes shortly after cataract extraction. Five representative cases are described in this report.

\section{Case reports}

\section{CASE 1}

A 75-year-old man was referred to our department for cataract surgery. He had an 11-year history of orally controlled diabetes mellitus and hypertension controlled by hypotensive medication. The findings on physical examination were normal. His visual acuity was finger counting in the right eye and 20/70 in the left. Applanation tonometry revealed normal intraocular pressure in both eyes. Slit-lamp examination showed a mature cataract in the right eye and progressive nuclear sclerosis in the left eye. Lens opacity of the right eye precluded fundal examination. Diabetic retinopathy, consisting of a few intraretinal haemorrhages and minute hard exudates, was observed in the left eye.

An uncomplicated intracapsular cataract extraction in the right eye was performed. Fundal examination on the day after surgery

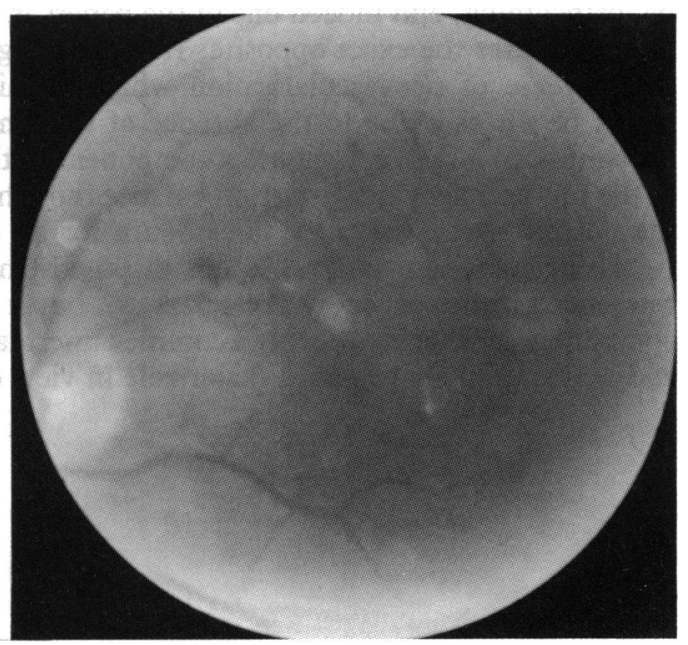

Figure $1 B$ 
revealed a few small intraretinal haemorrhages in the posterior pole. Over the next two weeks he developed cystoid macular oedema. Visual acuity was 20/200.

After one month, the visual acuity in the operated eye had deteriorated to finger counting. Fundal examination disclosed aggravation of the pre-existing diabetic retinopathy, with diffuse macular oedema and a marked increase of the intraretinal haemorrhages and hard exudates. The latter now formed a dense ring adjacent to the superior vascular arcade and extended to the fovea (Fig 1A). At the same time the nonoperated left eye had remained stable (Fig 1B). Fluorescein angiography showed extensive leakage of dye in the posterior pole of the operated eye and only a small focus of leakage corresponding to the area of hard exudates in the fellow eye.

Grid argon laser photocoagulation was applied to the right eye. Examinations over the next few months revealed a gradual absorption of the hard exudates and formation of a foveal scar. Visual acuity one year after cataract extraction was 20/200.

The retina of the unoperated eye appeared stable over a follow-up period of two years; however, the cataract progressed and the vision declined to 20/200. A few dot haemorrhages and hard exudates were noted in the retina. In view of the postoperative deterioration of the diabetic retinopathy in the right eye focal argon laser photocoagulation was recommended for the left eye. However, because of opacities in the lens the treatment could not be completed, and the patient underwent an uneventful extracapsular cataract extraction in the left eye. Fundal examination on the day after surgery revealed diabetic retinopathy with a few dot and flame-shaped haemorrhages and minute hard exudates. Three months after surgery the amount of hard exudates and macular oedema had increased significantly, and grid argon laser photocoagulation was performed. The visual acuity 20/200. The macula showed atrophic changes, which were probably related to the resolved postoperative macular oedema.

CASE 2

A 78-year-old woman with a 20-year history of insulin-dependent diabetes mellitus was referred to our department for cataract surgery. One year earlier she had undergone argon laser

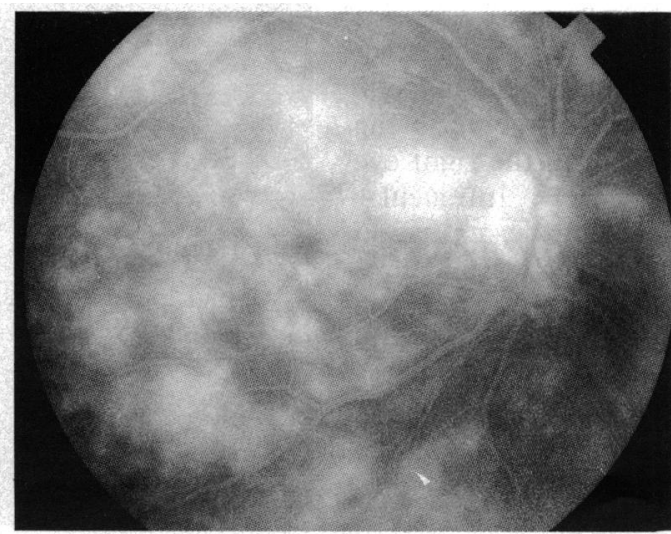

Figure 2A iridotomies in both eyes for narrow angle glaucoma. The intraocular pressure in both eyes was controlled without medication. Visual acuity was finger counting in the right eye and 20/70 in the left. Slit-lamp examination revealed patent iridotomies in both eyes, progressive nuclear sclerosis in the right eye, and mild nuclear sclerosis in the left eye. The fundus of the right eye could not be seen because of lens opacities. The left eye showed diabetic retinopathy, consisting of a few small dot haemorrhages.

An uncomplicated extracapsular cataract extraction with posterior chamber intraocular lens implantation was performed in the right eye. Fundal examination of the right operated eye on the day after surgery showed diabetic retinopathy, similar to that in the left eye, consisting of a few dot haemorrhages and microaneurysms. The vision improved to 20/40. Three months after surgery the visual acuity in the right eye had declined to 20/70 while remaining unchanged in the left eye. Fundal examination of the operated eye showed diffuse retinal thickening in the macular area with superimposed cystoid macular oedema. Fluorescein angiography of that eye during the early arteriovenous phase showed numerous prominent microaneurysms and dilatation of the capillary bed in the entire posterior pole as well as in the peripapillary capillary network. Late angiograms showed extensive fluorescein leakage in the entire posterior pole, extending from the peripapillary area towards the vascular arcade. Superimposed perifoveal cystoid macular oedema was also noted (Fig 2A). Although fluorescein angiography of the left eye also disclosed foci of dye leakage in the posterior pole, it was not as prominent as in the operated eye and did not extend beyond the vascular arcades (Fig 2B). Grid argon laser photocoagulation was applied in the right eye because of the clinically significant macular oedema seen on ophthalmoscopy and the extensive fluorescein leakage observed in the entire posterior pole. The oedema subsequently resolved and the vision improved to $20 / 30$.

CASE 3

A 70-year-old man with a 20-year history of orally controlled diabetes mellitus was referred to our department for cataract surgery. His medical history included cholecystectomy for acute cholecystitis one year earlier. The visual

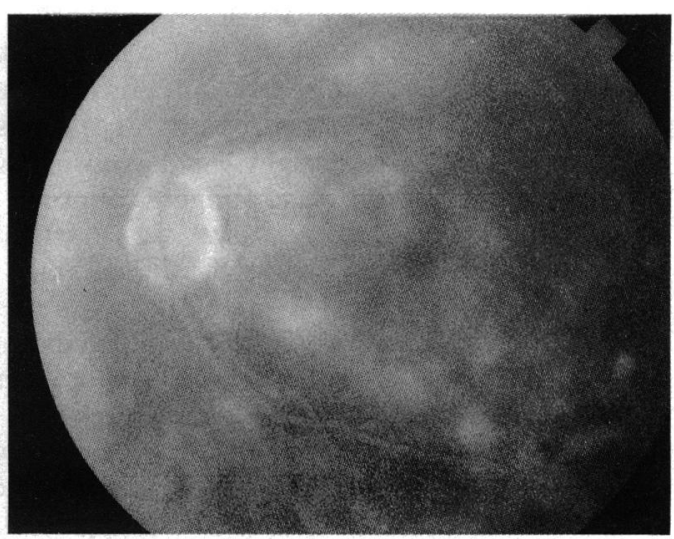

Figure 2B
Figure 2 Case 2. A: Late arteriovenous phase of fluorescein angiography three months after surgery in the right eye shows diffuse extending beyond the vascular arcades and to the peripapillary region. $B$. Fluorescein angiography of significantly fewer foci of less intense leakage. igure $2 A$ 
Figure 3 Case 3. A: Preoperative late phase of angiogram shows a few microaneurysms (small arrow) and leakage adjacent to vascular arcades (long arrows). B:

Postoperative late angiogram shows extensive leakage at the posterior pol and superimposed cystoid macular oedema. C: Late angiogram of the nonoperated eye at that time shows microaneurysms and mild leakage.
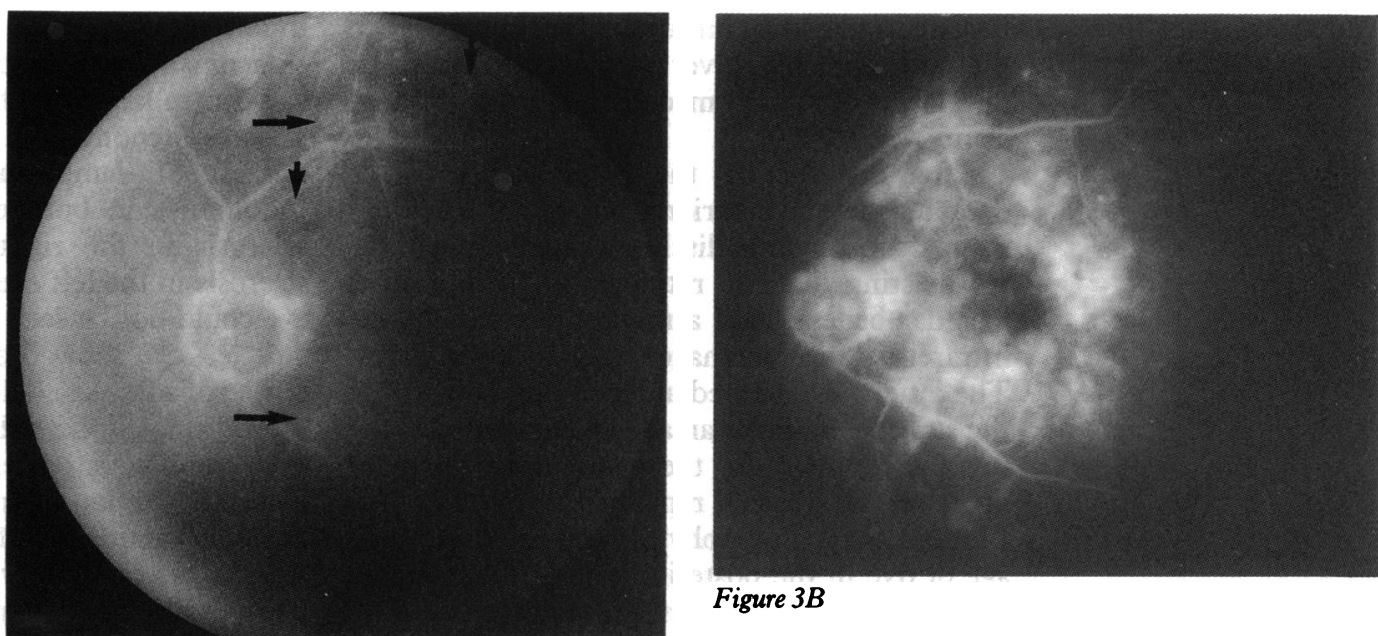

Figure 3B

Figure 3A

acuity was $20 / 40$ in the right eye and $20 / 200$ in the left. Applanation tonometry revealed normal intraocular pressure in both eyes. Slit-lamp examination disclosed minimal nuclear sclerosis in the right eye and progressive nuclear sclerosis in the left. In both eyes funduscopy showed mild diabetic retinopathy consisting of microaneurysms and a few small dot haemorrhages. Preoperative fluorescein angiography of the left eye showed a few microaneurysms and mild dye leakage adjacent to the vascular arcades (Fig 3A). The patient underwent an uncomplicated extracapsular cataract extraction in the left eye. Fundal examination of the operated eye immediately after surgery disclosed a few microaneurysms and small dot haemorrhages. Six weeks later funduscopy of that eye revealed cystoid macular oedema. Fluorescein angiography revealed multiple foci of dye leakage in the entire posterior pole including the peripapillary area, with superimposed cystoid macular oedema (Fig 3B). At the same time the non-operated eye showed a few microaneurysms and mild fluorescein leakage (Fig 3C). Visual acuity was $20 / 40$ in both eyes. Since ophthalmoscopy the oedema in the operated eye has been very mild and the vision showed a tendency to improve, laser treatment was deferred, and the patient was put on indomethacin drops. Three months after surgery the macular oedema had resolved, and the final visual acuity of 20/40 has remained stable since that time.

CASE 4

A 63-year-old man was referred for cataract extraction. His medical history revealed diabetic neuropathy of the posterior tibial nerve in the right leg. His vision was $20 / 40$ in the right eye and finger counting in the left. Intraocular pressure was normal. Slit-lamp examination showed mild cataract in the right eye and progressive cataract in the left. Fundal examination of the right eye disclosed diabetic retinopathy consisting of microaneurysms and dot and flame shaped haemorrhages. Although the left fundus could not be clearly visualised because of the cataract, it was possible to detect diabetic retinopathy, which appeared to be of similar severity to that in the right eye.
The patient underwent an uncomplicated extracapsular cataract extraction with intraocular lens implantation in the left eye. Two months after surgery funduscopy of the operated eye revealed cystoid macular oedema, his vision declined from 20/40 to 20/70, and laser treatment was considered. However, it was three months before the patient again presented himself for follow-up examination, and by that time the vision in the left eye had improved to $20 / 40$. Although ophthalmoscopy indicated that the clinical oedema had resolved, angiography disclosed persistent cystoid macular oedema. A year and a half after the operation the cataract in the unoperated right eye had progressed, and he was again scheduled for surgery. Although the fundus could be only vaguely visualised preoperatively, it was possible to observe diabetic retinopathy consisting of haemorrhages (Fig 4, top left). The patient underwent extracapsular cataract extraction with implantation of an intraocular lens in the right eye. One month after surgery funduscopy revealed an increased number of haemorrhages and minute hard exudates, a few cotton-wool exudates, and cystoid macular oedema (Fig 4, top right). Fluorescein angiography of the operated eye revealed dye leakage in the entire posterior pole extending to the vascular arcades. At the peripheral retina non-perfused areas were also

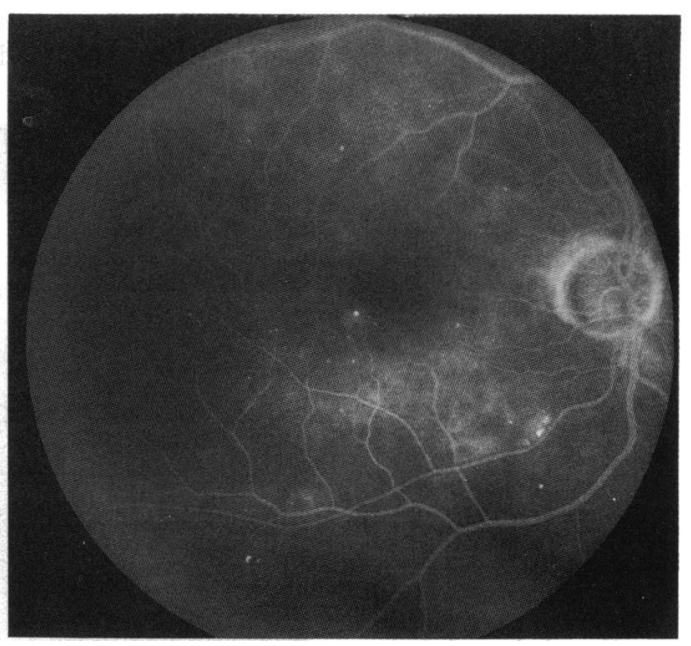

Figure 3C 
Figure 4 Case 4. Top left: Preoperative

ophthalmoscopic appearance of the right eye, showing the presence of haemorrhages. Top right: Postoperative preangiographic picture shows microaneurysms, numerous dot and flame shaped haemorrhages and minute hard exudates.

Centre left: Angiogram of the early arteriovenous phase shows areas of blocked

fluorescence corresponding to haemorrhages and numerous microaneurysms. Centre right: Mid-arteriovenous phase shows dye leakage from microaneurysms and dilated capillaries, as well as peripheral areas of capillary non-perfusion. Bottom left:

Late phase angiogram shows extensive leakage over the entire posterior pole, with superimposed macular oedema. Bottom right: Late phase angiogram at the peripapillary area shows non-perfused areas surrounded by foci of fluorescein leakage.

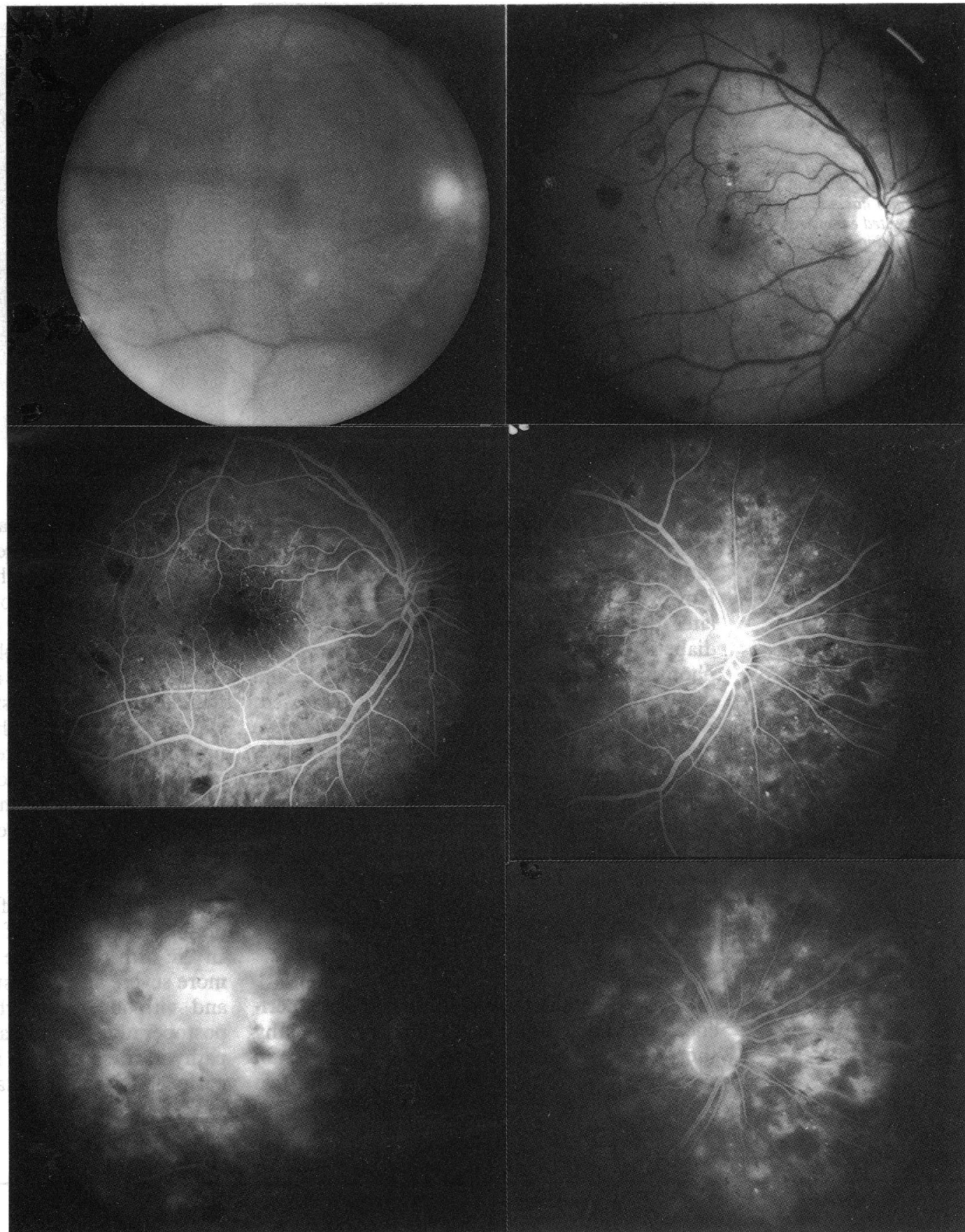

observed (Fig 4, centre, bottom). Visual acuity was 20/30. Because of the good vision in this eye, as well as the spontaneous resolution of the macular oedema and the final good visual results in the previously operated eye, laser treatment was deferred, and the patient was followed up closely. Three months later the macular oedema had resolved. Two years after surgery his vision was 20/30, there was no clinical macular oedema, and the areas of retinal ischemia had not progressed.

\section{CASE 5}

A 71-year-old man was referred for cataract extraction. His visual acuity was finger counting in the right eye and 20/50 in the left. Slit-lamp examination showed progressive cataract in the right eye and mild nuclear sclerosis in the left eye. Funduscopy through the cataracts revealed similar bilateral diabetic retinopathy with multiple dot haemorrhages, microaneurysms, and dilated veins. However, the left eye could be more clearly visualised than the right, and early new vessels were noted to come off the top edge of the optic disc.

An uneventful intracapsular cataract extraction was performed in the right eye. Fundal examination one week later disclosed numerous flame shaped haemorrhages and some soft exudates. One month after surgery proliferative diabetic retinopathy and vitreous haemorrhage were noted. The fundal appearance of the nonoperated eye had remained unchanged (Fig 5A). Once the vitreous haemorrage in the operated eye had partially cleared and the retina was visible, it was possible to discern disc neovascularisation, flame shaped haemorrhages, and soft and hard exudates in the posterior pole (Fig 5B). Argon laser panretinal photocoagulation was 
Figure 5: Case 5. A: Ophthalmoscopic appearance of the right eye three months after cataract surgery, showing vitreous haemorrhage and disc neovascularisation. $B$ : Ophthalmoscopic appearance of the left non operated eye at the same time shows small haemorrhages and suspected early new vessels coming off the top edge of the optic disc.

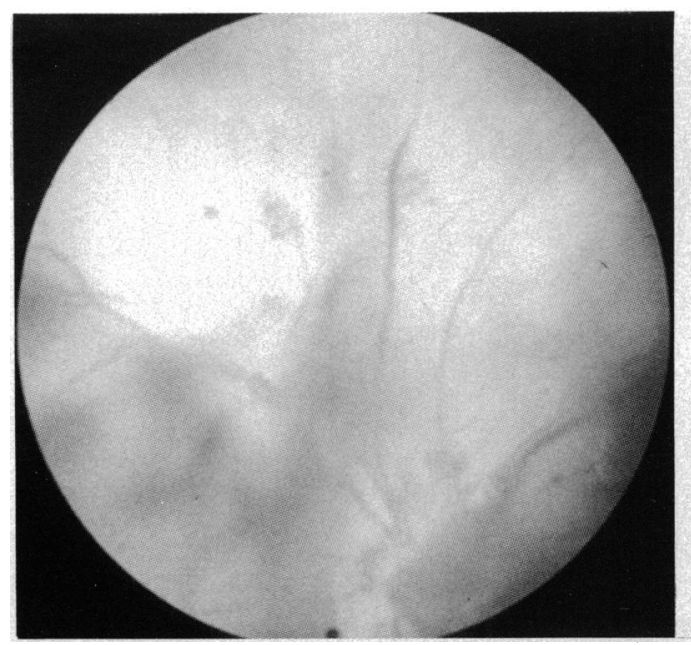

Figure 5A

performed. The final visual acuity was $20 / 200$.

Over the next three years there were no further retinal changes in the non-operated fellow eye. However, a follow-up examination three years later disclosed progression of the proliferative diabetic retinopathy in that eye. Panretinal photocoagulation was therefore performed, and the new blood vessels subsequently regressed. Six years after cataract extraction in the right eye the vision in the left eye had deteriorated to finger counting, and extracapsular cataract extraction with intraocular lens implantation was performed. No postoperative progression of the diabetic retinopathy was observed during the following year. The final visual acuity in that eye was $20 / 50$.

\section{Discussion}

All five patients described in this report experienced rapid deterioration of diabetic retinopathy shortly after cataract surgery, resulting in asymmetric severity of the disease in the two

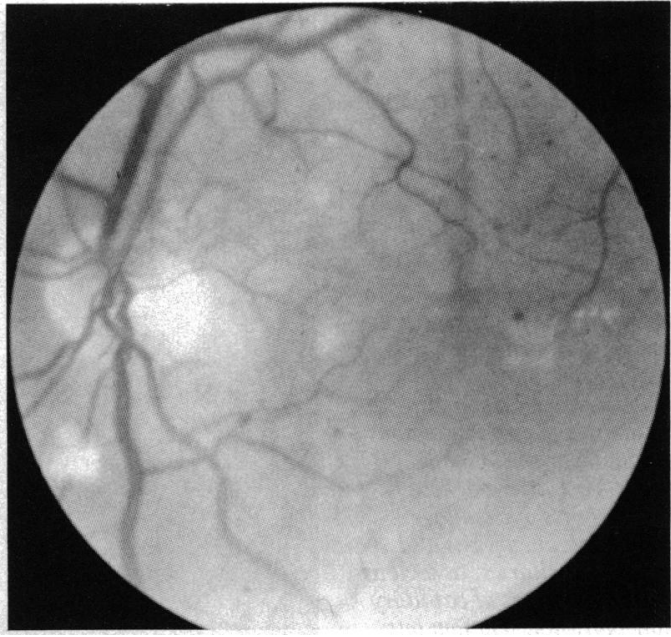

Figure 5B

eyes. In the first four cases the deterioration was manifested by the increased number of dot and flame shaped haemorrhages and hard exudates and by the appearance of retinal oedema, marked retinal thickening, and cystoid macular oedema. Fluorescein angiography of the affected eyes showed diffuse leakage in the entire macular area with superimposed cystoid macular oedema, as well as leakage from the peripapillary capillary networks. Severe extensive macular oedema occurring after cataract surgery was reported also by Jaffe and Burton. ' In our series, however, cases 4 and 5 also developed retinal ischaemia, which was manifested ophthalmoscopically by preproliferative signs such as flame shaped haemorrhages and soft exudates, and angiographically by areas of capillary non-perfusion. In the fifth patient the ischaemic changes were more severe and consisted of neovascularisation and vitreous haemorrhage. In summary, the postoperative deterioration of diabetic retinopathy in these patients included vascular hyperpermeability and leakage as well as capillary

Table 1 Clinical findings before and after cataract surgery

\begin{tabular}{|c|c|c|c|c|c|c|c|c|c|c|c|c|c|c|}
\hline \multirow{3}{*}{$\begin{array}{l}\text { Case } \\
\text { no. }\end{array}$} & \multirow{3}{*}{$\begin{array}{l}\text { Age (yr) } \\
\text { and sex }\end{array}$} & \multirow{3}{*}{$\begin{array}{l}\text { Diabetes } \\
\begin{array}{l}\text { Duration } \\
(y r)\end{array}\end{array}$} & \multirow[b]{3}{*}{ Treatment } & \multirow{2}{*}{\multicolumn{2}{|c|}{ Other diseases }} & \multicolumn{4}{|c|}{ Visual acuity } & \multirow{3}{*}{$\begin{array}{l}\text { Type of } \\
\text { surgery }\end{array}$} & \multirow{2}{*}{\multicolumn{2}{|c|}{ Status of $D R$}} & \multirow{2}{*}{\multicolumn{2}{|c|}{ Treatment }} \\
\hline & & & & & & Pre- & Post- & Follow & & & & & & \\
\hline & & & & Systemic & Ocular & op. & $o p$ & up & Final & & Atop. & Post-op. & $A-L$ & Others \\
\hline \multirow[t]{2}{*}{1} & $75 / \mathrm{M}$ & 11 & Oral & $\begin{array}{l}\text { Hyper- } \\
\text { tension }\end{array}$ & - & $\mathrm{CF}$ & $20 / 200$ & $\mathrm{CF}$ & $20 / 200$ & ICCE & $\begin{array}{l}\text { Dot haemorrhages } \\
\text { Hard exudates }\end{array}$ & $\begin{array}{l}\text { Dot + flame haemorrhages } \\
\text { Massive exudates, ME, } \\
\text { CME }\end{array}$ & $\begin{array}{l}\text { Post-operative } \\
\text { Grid }\end{array}$ & \\
\hline & $77 / M$ & 13 & Oral & $\begin{array}{l}\text { Hyper- } \\
\text { tension }\end{array}$ & - & CF & $20 / 200$ & $20 / 200$ & $20 / 200$ & $\mathrm{ECCE}+\mathrm{IOL}$ & $\begin{array}{l}\text { Dot haemorrhages } \\
\text { Hard exudates }\end{array}$ & $\begin{array}{l}\text { Dot + flame haemorrhages } \\
\text { Massive exudates, ME, } \\
\text { CME }\end{array}$ & $\begin{array}{l}\text { Post-operative } \\
\text { Grid }\end{array}$ & \\
\hline 2 & $78 / \mathrm{F}$ & 20 & Insulin & - & $\begin{array}{l}\text { NAG } \\
\text { ALI }\end{array}$ & $\mathrm{CF}$ & $20 / 40$ & $20 / 70$ & $20 / 30$ & ECCE +IOL & $\begin{array}{l}\text { Microaneurysms } \\
\text { Dot haemorrhages }\end{array}$ & ME, CME & $\begin{array}{l}\text { Post-operative } \\
\text { Grid }\end{array}$ & \\
\hline 3 & $70 / M$ & 20 & Oral & $\begin{array}{c}\text { Cholecyst- } \\
\text { ectomy }\end{array}$ & - & $20 / 200$ & $20 / 40$ & $20 / 40$ & $20 / 40$ & $\mathrm{ECCE}+\mathrm{IOL}$ & $\begin{array}{l}\text { Microaneurysms } \\
\text { Dot haemorrhages }\end{array}$ & $\mathrm{ME}, \mathrm{CME}$ & & $\begin{array}{l}\text { Indomethacin } \\
\text { drops }\end{array}$ \\
\hline \multirow[t]{2}{*}{4} & $63 / M$ & 9 & Oral & \multirow[t]{2}{*}{$\begin{array}{l}\text { Diabetic } \\
\text { neuro- } \\
\text { pathy }\end{array}$} & - & CF & $20 / 40$ & $20 / 70$ & $20 / 40$ & $\mathrm{ECCE}+\mathrm{IOL}$ & $\begin{array}{l}\text { Microaneurysms } \\
\text { Dot haemorrhages }\end{array}$ & $\begin{array}{l}\text { Dot + flame haemorrhages } \\
\text { ME, CME, Non-perfusion }\end{array}$ & - & \\
\hline & $64 / M$ & 10 & Oral & & - & $20 / 200$ & $20 / 30$ & $20 / 30$ & $20 / 30$ & ECCE +IOL & $\begin{array}{l}\text { Microaneurysms } \\
\text { Dot haemorrhages }\end{array}$ & $\begin{array}{l}\text { Dot + flame haemorrhages } \\
\text { ME, CME, Non-perfusion }\end{array}$ & - & \\
\hline \multirow[t]{2}{*}{5} & $71 / M$ & 1 & Oral & $\begin{array}{l}\text { S/A MI } \\
\text { Ischae- } \\
\text { mic } \\
\text { heart } \\
\text { disease }\end{array}$ & - & $\mathrm{CF}$ & $20 / 200$ & $\mathrm{CF}$ & $20 / 200$ & ICCE & NVD? & $\begin{array}{l}\text { NVD, vitreous } \\
\text { haemorrhage }\end{array}$ & Post-op. PRP & \\
\hline & $77 / M$ & 7 & Diet & $\begin{array}{l}\text { Chronic } \\
\text { lung } \\
\text { disease }\end{array}$ & - & $\mathrm{CF}$ & & - & $20 / 50$ & ECCE + IOL & PDR, S/A PRP & PDR, S/A PRP & - & \\
\hline
\end{tabular}

Op, operation; CF, counting fingers; DR, diabetic retinopathy; ICCE, intracapsular cataract extraction; ECCE, extracapsular cataract extraction; IOL, intraocular lens; A-L, argon laser photocoagulation; ME, macular oedema; CME, cystoid macular oedema; NAG, narrow angle glaucoma; ALI, argon laser iridotomy; NVD, neovascularisation on the disc; PDR, proliferative diabetic retinopathy; PRP, panretinal photocoagulation; S/A, state after; MI, myocardial infarction. 
closure, retinal ischaemia, and neovascularisation.

Previous authors have pointed out that postoperative progressive changes of diabetic retinopathy occur mainly in patients in whom diabetic retinopathy was already present prior to surgery. ${ }^{1-36}$ However, the mechanisms involved in acceleration of diabetic retinopathy after cataract extraction in elderly patients is unknown. Local factors which might account for the sudden vasculopathic deterioration after cataract extraction are: (a) the absence of an angiogenic inhibitory factor which is present in the lens, ${ }^{8}(b)$ postoperative intraocular inflammation mediated by leukotrienes, ${ }^{9}(c)$ reduced secretion of vasoinhibitory substances present in the retinal pigment epithelium, ${ }^{10}$ and $(d)$ increased synthesis of the endothelin that functions as an angiogenic agent within the iris stroma. " The possible role of each of these factors in the sudden aggravation of diabetic retinopathy after cataract surgery deserves investigation. Whatever the aetiology, the retinal capillaries appear to make a pathological response to the surgery, with resulting disruption of the blood-retinal barrier and/or occlusion of the retinal capillaries. The clinical correlates of these events are transudation and macular oedema and/or induction of retinal ischaemia leading to neovascularisation.

The cases reported here highlight some of the problems of treating diabetic patients with cataract. The first problem relates to the timing of cataract surgery. Since surgery may lead to aggravation of diabetic retinopathy, it may be preferable to delay it as long as possible. On the other hand opacity of the lens can be an obstacle to laser treatment. It can also preclude accurate assessment of the retinopathy, and in particular the amount of retinal ischaemia. Although fluorescein angiography is sometimes helpful in the assessment of retinal ischaemia, even in cases with significant lens opacities, underestimation of the severity of the disease is not uncommon.

Another problem relates to the difficulty of differentiating between aphakic or pseudophakaic cystoid macular oedema and diabetic cystoid macular oedema. Indeed, sometimes it is impossible to distinguish between them, since cystoid macular oedema occurs in both conditions. However, as the present series shows, compared with the perifoveal fluorescein leakage seen in non-diabetic aphakic eyes the fluorescein leakage in diabetic eyes is more extensive and extends towards the vascular arcade and peripapillary region. In this series diabetic retinopathy was defined as 'deteriorated' only when ophthalmoscopy disclosed wide areas of retinal thickening and angiography revealed extensive dye leakage from visible microaneurysms in addition to perifoveal leakage from the capillary bed that appears in the general aphakic or pseudophakic cystoid macular oedema. It is not unusual to find a discrepancy between the ophthalmoscopic picture of mild cystoid macular oedema accompanied by good vision and the angiographic appearance of marked fluorescein leakage (cases 3 and 4). Moreover, it is difficult to predict whether the postoperative cystoid macular oedema will resolve spontaneously (as in cases 3 and 4) or lead to permanent damage. This difficulty may make it hard to decide whether or not to recommend laser treatment.

It has been suggested that extracapsular cataract extraction reduces the risk of postoperative diabetic complications and is therefore preferable to the intracapsular technique. ${ }^{12-14}$ However, in our first patient the postoperative aggravation of diabetic retinopathy was similar in both eyes, even though one eye underwent an intracapsular and the other an extracapsular procedure. Our experience with other operated patients further supports our observation that, although deterioration of diabetic retinopathy is less common after extracapsular than after intracapsular cataract extraction, the extracapsular procedure does not necessarily mean that aggravation of pre-existing diabetic retinopathy can be prevented.

The question whether or not to perform preventive preoperative laser photocoagulation in patients with diabetic retinopathy is also of some concern. In our fifth patient, aggravation of retinal neovascularisation in the first operated eye was evident within a month after surgery. In the fellow non-operated eye retinal neovascularisation showed significant progression only three years later; prior to cataract extraction in that eye, panretinal laser photocoagulation was applied and the new blood vessels then regressed. The diabetic retinopathy in that eye did not progress after surgery. This raises an important question: should those patients with cataracts but with adequate fundus visualisation receive preventive laser treatment even when the preoperative severity of diabetic retinopathy does not meet the criteria for laser treatment outlined by the Diabetic Retinopathy Multicenter Studies? The answer to this question must await the findings of suitably controlled studies.

Our findings emphasise the need for a careful assessment of the diabetic retinopathy prior to surgery. This should include fluorescein angiography, which can be helpful even when visualisation of the fundus is impaired. After surgery follow-up examinations to detect any aggravation of diabetic retinopathy should be performed at weekly or two-weekly intervals for the first three months and every four weeks for the next three months. Fluorescein angiography should be performed during the first month of followup, as well as three and six months after surgery, even in the absence of clinical signs of deterioration of diabetic retinopathy. Since it is more sensitive than ophthàlmoscopy as a diagnostic tool, it should also be performed whenever such deterioration is suspected. If aggravation of diabetic retinopathy following cataract surgery is detected early and treated with laser photocoagulation, the final visual outcome may be improved.

1 Kirmani TH. Prognosis of cataract extraction in diabetics. Am F Ophthalmol 1964; 57: 617-9.

2 Caird FI, Hutchinson M, Pirie A. Cataract extraction and diabetes. Brf Ophthalmol 1965; 49: 466-71.

3 Clayman HM, Jaffe NS, Light DS. - Lens implantation and dayman HM, Jaffe NS, Light DS. Lens implantation
diabetes mellitus. Am $\mathcal{f}$ Ophthalmol 1979; 88: $990-2$.

4 Kennedy JE, Lim ASM, Ang BC. Posterior chamber intra-

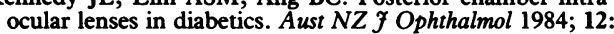
253-6.

5 Straatsma BR, Petit TH, Wheeler N, Miyamasu W. Diabetes mellitus and intraocular lens implantation. Ophthalmolog 1983; 90: 336-43. 
6 Apple DJ, Mamalis N, Loftfield K, et al. Complications of intraocular lenses. A historical and histopathological review. intraocular lenses. A historical and
Surv Ophthalmol 1985; 29: 1-54.

Surv Ophthalmol 1985; 29: 1-54.
7 Jaffe GJ, Burton TC. Progression of nonproliferative diabetic retinopathy following cataract extraction. Arch Ophthalmol 1988; 106: 745-9.

8 Williams GA, Eisenstein R, Schumacher B, Hsiao KC, Grant $D$. Inhibition of vascular endothelial cell growth in the lens. Am $\mathcal{F}$ Ophthalmol 1984; 97: 366-71.

9 Milch FA, Yannuzzi LA. Medical and surgical treatment of aphakic cystoid macular edema. Int Ophthalmol Clin 1987; 27: 205-17.

10 Glaser BM, Campochiaro PA, David JL Jr. Retinal pigment epithelial cells release an inhibitor of neovascularization. Arch Ophthalmol 1985; 103: 1870-5.
11 MacCumber M, Ross C, Delayre T, Synder S, Glaser BM. Ocular synthesis of and response to endothelin, a potent
vasoconstrictive peptide. Second International Symposium vasoconstrictive peptide. Second International Symposium 1989: 33.

12 Alpar JJ. Cataract extraction and diabetic retinopathy. $\mathcal{f} \mathrm{Am}$ Intraocul Implant Soc 1984; 10: 433-7.

13 Alpar JJ. Diabetes, cataract extraction and intraocular lenses. f Cataract Refract Surg 1987; 13: 43-6.

14 Poliner LS, Christianson DJ, Escoffery RF, Kolker AE, Gordon ME. Neovascular glaucoma after intracapsular and extracapsular cataract extraction in diabetic patients. $A m \mathcal{F}$ Ophthalmol 1985; 100: 637-43. 